University of Nebraska - Lincoln

DigitalCommons@University of Nebraska - Lincoln

2021

\title{
Evaluation of Models Used to Predict Dry Matter Intake in Forage- Based Diets
}

Aksel Wiseman

Andrea K. Watson

Rick Stock

Terry Klopfenstein

Follow this and additional works at: https://digitalcommons.unl.edu/animalscinbcr

Part of the Large or Food Animal and Equine Medicine Commons, Meat Science Commons, and the Veterinary Preventive Medicine, Epidemiology, and Public Health Commons

This Article is brought to you for free and open access by the Animal Science Department at DigitalCommons@University of Nebraska - Lincoln. It has been accepted for inclusion in Nebraska Beef Cattle Reports by an authorized administrator of DigitalCommons@University of Nebraska - Lincoln. 


\section{Evaluation of Models Used to Predict Dry Matter Intake in Forage-Based Diets}

\author{
Aksel Wiseman \\ Andrea Watson \\ Rick Stock \\ Terry Klopfenstein
}

\section{Summary with Implications}

Accurately predicting intake is critical to model performance of cattle in order to formulate diets to meet nutritional requirements. Modeling systems must be accurate in order to provide correct information to producers. Multiple studies with growing cattle consuming forage-based diets were summarized. Actual gain and weights of the cattle were used to determine predicted dry matter intake using the Beef Cattle Nutrient Requirements Model (2016). The predicted dry matter intakes were compared to observed dry matter intakes to determine accuracy of the prediction model. The model over predicted intakes at low TDN and under predicted intakes at higher TDN values, with the interaction at approximately $64 \%$ TDN. The Beef Cattle Nutrient Requirements Model (2016) does not accurately predict dry matter intake of growing calves consuming forage-based diets.

\section{Introduction}

Forage-based diets are primarily fed to calves to promote growth rather than fat deposition, which allows for greater carcass weights without becoming overly fat during finishing. The challenge to using forage-based diets is being able to provide adequate energy, protein, and minerals to meet the growth requirements of these calves. In order to meet these requirements, it is essential to predict dry matter intake (DMI). The concept of modeling is to use previous data to create a tool that can predict DMI, protein and energy requirements, and performance of growing cattle. Models can then be used in diet formulation to

(c) The Board Regents of the University of Nebraska. All rights reserved.

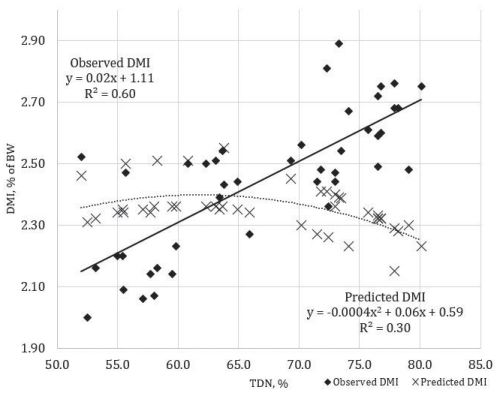

Figure 1. Observed versus predicted dry matter intake. Plot of observed (43 treatment means) and BCNRM (2016) predicted dry matter intake for forage based diets (hay or corn silage based with and without distillers grains) with TDN of 52 to $80 \%$.

ensure optimal performance of the calves. There are different modeling tools that are currently available for use, but the most common is the Beef Cattle Nutrient Requirements Model (BCNRM) (2016). This is the newest version of what has commonly been referred to as the National Research Council (NRC) model. Our hypothesis was that the data used to build the current modeling system was based primarily on studies that were high-energy growing diets or finishing diets, and these data were extrapolated to fit high-forage, low-energy diets. Thus, the objective was to evaluate the current modeling tool's ability to predict DMI in high-forage, low-energy diets.

\section{Procedure}

Experiments used were conducted at the Eastern Nebraska Research and Extension Center, near Mead, NE, utilizing similar protocols. Studies included calves (8 to 12 hd per treatment mean) that were individually fed using the Calan gate system, or calves that were pen-fed with 8 to 12 head per pen and 6 to 10 pens per treatment. Initiation of studies occurred directly after receiving or 2 to 3 months later following a period of grazing cornstalks. To determine initial and ending body weights, calves were

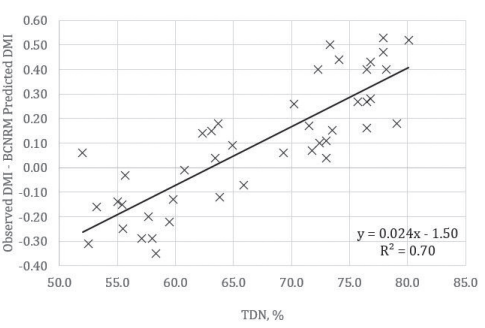

Figure 2. Difference between Observed and Predicted DMI relative to TDN. Plot of observed (43 treatments means) dry matter intake minus BCNRM (2016) predicted dry matter intake for forage-based diets (hay or corn silage based with or without distillers grains) with TDN of 52 to $80 \%$

limit-fed for 3 to 5 days to minimize the effects of rumen fill. Feeds and feed refusals were sampled weekly to determine DMI. Cattle were fed ad libitum in all studies. Actual body weights (BW) and average daily gain (ADG) were entered into the BCNRM (2016) model to determine predicted intake of the cattle during the study period. The predicted intake was then compared with the observed intake of the cattle to determine the accuracy of the prediction model of the data set. The difference between observed intake and predicted intake was determined as Observed DMI minus BCNRM Predicted DMI.

Of the 77 treatment means that were developed, 43 were utilized in this evaluation. Studies were grouped into 1 of 4 categories: Control (traditional forage-based diets with no distillers grains [DG]), Control DG (forage-based diets with DG), Corn Silage (corn silage-based diets), and Corn Silage DG (corn silage-based diets with DG). Due to a limited number of Corn Silage studies without DG, the Corn Silage and Corn Silage DG categories were combined.

\section{Results}

Observed and predicted intake were plotted across calculated TDN values to evaluate their relationship (Figure 1). As 
Table 1. Observed versus predicted dry matter intake of different diet types ${ }^{1}$

\begin{tabular}{lcc}
\hline & $P$-Value & $\mathrm{R}^{2}$ \\
\hline Overall Means $^{2}$ & 0.27 & 0.06 \\
Control $^{3}$ & 0.05 & 0.36 \\
Control DG $^{4}$ & 0.02 & 0.55 \\
Corn Silage & 0.16 & 0.28 \\
\hline${ }^{1}$ Comparison of observed versus predicted dry matter intake \\
using the BCNRM (2016) model \\
${ }^{2}$ All treatment means developed, $\mathrm{n}=43$ \\
${ }^{3}$ Traditional forage-based diets with no distillers grains $\mathrm{n}$ \\
$=16$ \\
${ }^{4}$ Traditional forage-based diets with distillers grains, $\mathrm{n}=13$ \\
${ }^{5}$ Corn silage-based diets with and without distillers grains, \\
$\mathrm{n}=14$
\end{tabular}

TDN increased, observed DMI increased linearly $(P<0.01)$ while predicted DMI had a quadratic response $(P<0.01)$, increasing up to $64 \%$ TDN and then decreasing with increasing TDN. The differences in DMI suggest the model may not correctly account for differences in diet type. Another possibility is the model inaccurately limits DMI of forage based diets when TDN gets above $64 \%$. Because of the curvilinear response of the predicted DMI, the model may shift from a rumen fill limitation to an energetic fill around 64\% TDN. However, the observed data would not agree with this intake pattern.

The difference between the observed DMI and the predicted DMI were plotted at differing levels of TDN (Figure 2). As TDN increased from 52.5 to $80.1 \%$ the difference between observed and predicted intake increased linearly $(P<0.01)$. At approximately 64\% TDN, Observed DMIPredicted DMI = 0; therefore, the model over predicted DMI for TDN < 64\% and under predicted DMI in forage-based diets greater than $64 \%$ TDN.

Table 1 shows the strength of the model and the correlation between the predicted and actual intake of the overall treatment means and the different categories of diets. The model was not good at predicting intake of the overall means $\left(\mathrm{R}^{2}=0.06 ; P\right.$
Table 2. Observed versus predicted dry matter intake at different levels of $\mathrm{TDN}^{1}$

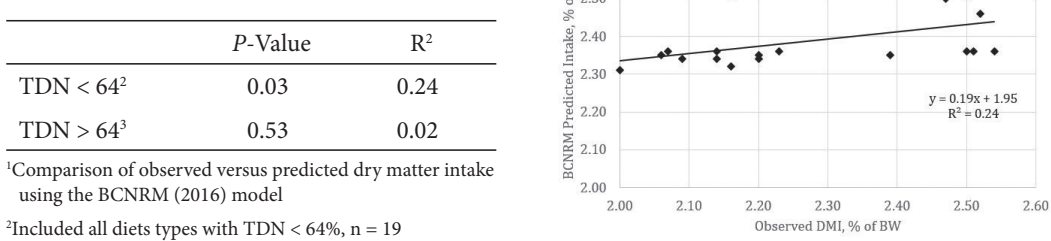

Figure 3. Observed versus Predicted DMI of Diets with TDN $<64$. Plot of observed (43 treatments means) and BCNRM (2016) predicted dry matter intake of forage based diets (hay and corn silage based diets with and without distillers grains) with TDN values lower than $64 \%$.

accurate within individual diet categories with the Control DG having the greatest correlation $\left(\mathrm{R}^{2}=0.55 ; P=0.02\right)$. However, the model had relatively low $\mathrm{R}^{2}$ values for all categories, suggesting it was not very accurate in predicting DMI of growing calves on any forage-based diets.

The lack of accuracy could be due to a lack of data points using high forage, low energy-based diets. The majority of the data used to build the BCNRM (2016) model may have been based on energy-dense growing diets or finishing based diets. The mechanisms that control intake are greatly different between these two types of systems and could be part of the reason that there were differences between the observed and predicted DMI when using forage-based diets.

Table 2 reports the strength of the model and the correlation between observed and predicted DMI of forage-based diets at differing TDN levels. Interestingly, when diets were less than $64 \%$ TDN $\left(\mathrm{R}^{2}=0.24 ; P\right.$ $=0.03)$, the model had a higher correlation between observed and predicted intake than when the TDN of the diet was greater than $64 \%\left(\mathrm{R}^{2}=0.02 ; P=0.53\right)$.

A plot of all diet types with TDN lower than $64 \%$ was evaluated to determine the accuracy of the BCNRM (2016) model for high-forage, low-energy diets. The slope of the line comparing observed and predicted DMI was 0.19 (Figure 3). If the model accurately predicted intake, the slope of the line would be close to 1.0. The low slope indicates there are flaws in the prediction equation being used for low TDN foragebased diets.

The model does not accurately predict DMI in forage-based growing calf diets. However, the reasons why are not clear. There could be a multitude of reasons for the differences between the observed and predicted DMI including a lack of data using forage-based diets, extrapolation from more energy dense diets, or alterations in fill mechanisms.

\section{Conclusion}

The current BCNRM (2016) model does not accurately predict DMI of growing calves consuming forage-based diets when compared with observed data from similar sources of cattle, utilizing similar experimental procedures. The lack of predicted accuracy creates challenges when formulating diets for growing cattle fed high-forage diets and should lead to further evaluation of the current modeling system.

Aksel Wiseman, graduate student

Andrea Watson, research assistant professor Rick Stock, professor

Terry Klopfenstein, professor, University of Nebraska-Lincoln Department of Animal Science 